\title{
The Hybrid Eco Vehicles (H.E.V), the Future of Indian Transport
}

\author{
Vaibhav Dixit ${ }^{1}$, Sachin Mishra ${ }^{2}$, Sourav Sharma ${ }^{3}$, Shiersh Pandey ${ }^{4}$ \\ ${ }^{1} \mathrm{Ug},{ }^{2} \mathrm{Ug},{ }^{3} \mathrm{Ug},{ }^{4} \mathrm{Ug}$, Me Department, Institute Of Information Technology \& Management, Gwalior, India.
}

\begin{abstract}
Today in India eco-friendly vehicles are spreading like fire. It includes CNG, LPG, and Electricity/Solar Powered engine/motor vehicles. Their efficiency is ranging from $75 \%-89 \%$ efficient as compared to gasoline \& diesel variants whose efficiency is almost $25 \%-35 \%$. But if we are taking about air compressed engines it is up to $95 \%$. Vehicles working on gasoline (petrol) and diesel engines produce exhaust like CO, $\mathrm{CO}_{2} \mathrm{~N}_{2} \mathrm{O}$ etc. Whereas vehicles working on CNG, LPG, Battery Power and Compressed Air don't produce any kind of exhaust or harmful gases. Now days, these eco-friendly vehicles are used on large scale which is used in Oil refineries, Civil Transport \& in many other forms. But hybrid vehicles comprising of bi-fuel injection are not used on Indian roads. We proposed to use these kinds of vehicles on the Indian roads, which in turn can give better economic efficiency and are in regular budget condition of the middle class families.
\end{abstract}

Keywords: CNG (Compressed Natural Gas), LPG (liquefied Petroleum Gas), Efficiency, Economic Efficiency.

\section{Introduction}

Compressed Air Vehicles and all other vehiclesrunning on Eco-Friendly fuels gives resultant better than the vehicles running on ordinary fuels such as petrol. These vehicles are cost effective as uses less amount of spare parts and are very cheap in manufacturing. Their maintenance cost cheap and parts are easily available on Automotive Parts Dealers. As per Indian roads and public requirements we require heavy duty vehicles and easy to use. The cost of fuel should not bother the daily running of the vehicle and moreover it should poses very low cost of public transportation and parking problems of our country. So after our survey we found that if we can create a vehicle that run on a very cheap fuel and the speed of vehicle is around $40-70 \mathrm{Km} / \mathrm{hr}$., it can be the next most wanted vehicle in the Indian Market.

\section{Alternative Fuels}

In convention we are using gasoline and diesel powered engines, which in output only provide us 25$35 \%$ thermal efficiency. The exhaust gases or mostly the greenhouse gases produced from burning these fuels are degrading our environment. There is no such efficient way to reduce this degradation, even long after we had utilized Catalytic convertors, there is no such impressive results observed. Now there is peak time to use the kind of fuels which provide us the same power or better work than previously used fuels without degrading our environment.

\subsection{Compressed Natural Gas}

Compressed natural gas (CNG)can be used in place of gasoline (petrol), diesel fuel and propane/LPG. CNG combustion produces fewer undesirable gases than the fuels mentioned above. It is safer than other fuels in the event of a spill, because natural gas is lighter than air and disperses quickly when released. CNG may be found above oil deposits, or may be collected from landfills or wastewater treatment plants where it is known as biogas. $\mathrm{CNG}$ is made by compressing natural gas (which is mainly composed of methane, $\mathrm{CH}_{4}$ ), to less than 1 percent of the volume it occupies at standard atmospheric pressure. It is stored and distributed in hard containers at a pressure of $20-25 \mathrm{MPa}(2,900-3,600 \mathrm{psi})$, usually in cylindrical or spherical shapes.

\subsection{Liquefied Petroleum Gas}

Liquefied petroleum Gas or liquid petroleum gas (LPG or LP gas), also referred to as simply propaneor butane, is a flammable mixture of hydrocarbon gases used as a fuel in heating appliances, cooking equipment, and vehicles.It is increasingly used as an aerosol propellant and a refrigerant, replacing chlorofluorocarbons in an effort to reduce damage to the ozone layer. When specifically used as a vehicle fuel it is often referred to as autogas. Varieties of LPG bought and sold include mixes that are primarily propane $\left(\mathrm{C}_{3} \mathrm{H}_{8}\right)$, primarily butane $\left(\mathrm{C}_{4} \mathrm{H}_{10}\right)$ and, most commonly, mixes including both propane and butane. In winter, the mixes contain more propane, while in summer, they contain more butane.In the United States, primarily two grades of LPG are sold: commercial propane and HD-5. These specifications are published by the Gas Processors Association (GPA)and the American Society of Testing and Materials (ASTM).Propane/butane blends are also listed in these specifications. 


\subsection{Compressed Air}

A compressed-air vehicle (CAV) is powered by an air engine, using compressed air, which is stored in a tank. Instead of mixing fuel with air and burning it in the engine to drive pistons with hot expanding gases; compressed-air vehicles use the expansion of compressed air to drive their pistons. One manufacturer claims to have designed an engine that is 90 percent efficient.Compressed-air propulsion may also be incorporated in hybrid systems, such as with battery electric propulsion. This kind of system is called hybrid-pneumatic electric propulsion. Additionally, regenerative braking can also be used in conjunction with this system.

\section{Design \& Achievements}

\subsection{Best Economy Design}

Compressed air has very low energy density, and once we start drawing air from a compressed air tank and pressure of the container drops very rapidly. The solution was provided by using cylinders in such an alignment that, once we draw air from the tank to the pistons, the spark plugs generates a high voltage spark which heats up the air presents inside the cylinder. After gaining energy, the air rapidly expands up and moves the piston from Top Dead Center to Bottom Dead Center. When the piston gradually rises up, it pushes out the burnt air from the exhaust valve. Again the exhaust valve will be connected to the inlet port of the other cylinder which is connected to the first cylinder on the same camshaft. This process will compress the exhaust air in the second cylinder. The exhaust port of second cylinder will be connected to the main compressed air tank. This will help in refilling the tank due to which the tank will not get empty. Hence the fuel is Air and the exhaust is negligible air. Hence it is completely ecofriendly and economical in both running and purchasing.

\subsection{Performance Design}

In this design module we were targeting performance and racing DNA of our ecofriendly vehicle. So we made some basic changes in the previous Economy Design. In this design both the pistons will work simultaneously with a common camshaft. When pressure is released from tank the piston will work as stated above but the tank will be connected to the exhaust port of $1^{\text {st }}$ cylinder instead of $2^{\text {nd }}$ one. Then all mechanism will work as previous spectra but the $2^{\text {nd }}$ cylinder's exhaust port will be connected to a Turbocharger. Which in turn provide large amount of compressed air into the $1^{\text {st }}$ cylinder directly. This method will boost up the performance of the vehicle with better efficiency mechanically.

\subsection{Hybrid Design}

Hybrid design will consist of bi-fuel injection system accompanied by an electronic fuel control module. This deign comprises of same set of vehicle but with two fuel used simultaneously. CNG and Compressed Air will be used as combination. When the engine is working on compressed air, the electronic control module will disable the CNG relay, whereas when it's switched to CNG supply the compressed air tank will be disconnected from the entire system. By this method, in case of any failure of primary air supply system the vehicle will be in running state until it's been repaired. The primary motive of hybrid system is to provide best in class economy and performance at the same time. Compressed Air system will provide best efficiency and if implemented with CNG could tremendously increase the vehicle's performance. That means even small size vehicle of low cubic capacity can provide better efficiency and high speed performance at the same time.

\subsection{Achievements}

- In India refueling is available on every petrol pump\& street air filling vendors for air compression engines and moreover CNG filling stations are been setup in every major city.

- Cost of compressed air is almost next to negligible and cost of CNG is much cheaper than petrol/diesel.

- Efficiency of CNG \& Compressed Air Vehicles is much better than the ordinary petrol \& diesel engines.

- Cost of production will be less as this system installation required less amount of parts as compared to ordinary systems available in the market.

- Running cost of these vehicles is very less.

- It is totally ecofriendly no more costly catalytic convertors are to be utilized.

- These vehicles can provide better efficiency and performance at the same time, no need to add any other accessories so to gain all features under the same element.

- On Indian roads, it can change the way of ordinary public transport system. For example: Imagine a bus of capacity 50 people transporting with our Hybrid system, the cost per head will be smashed directly by $35-50 \%$ of today's market price.

- On an individual level, these vehicles can be recharged from home Air pumps, which can fill the entire tank in 5 minutes consisting of more than 200Psi pressure in less than 8 Rupees, which in turn 
can run the vehicle for approx. $60 \mathrm{Km}$. Means travelling $1 \mathrm{~km}$ in less than 1 Rupee in this $21^{\text {st }}$ Century at Economic Crisis Level is no longer a dream for an individual.

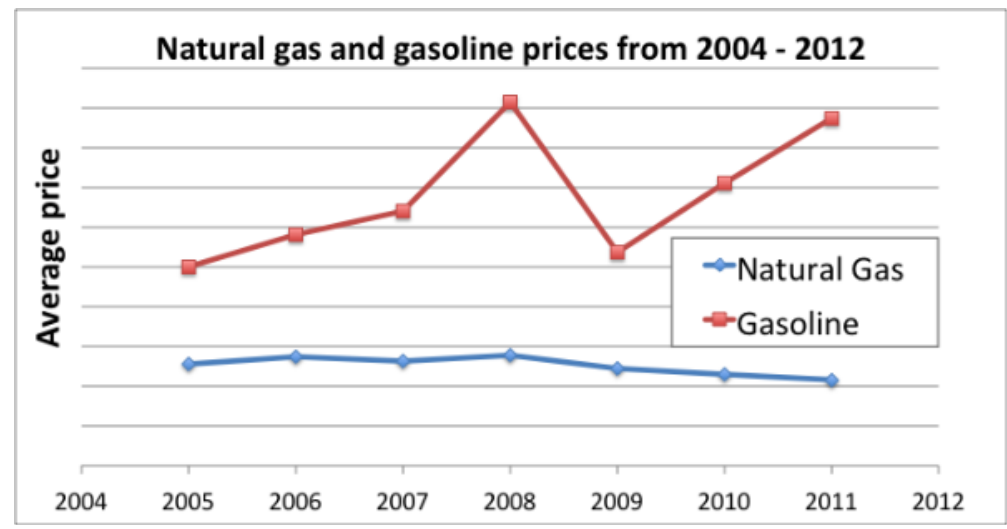

Figure 1

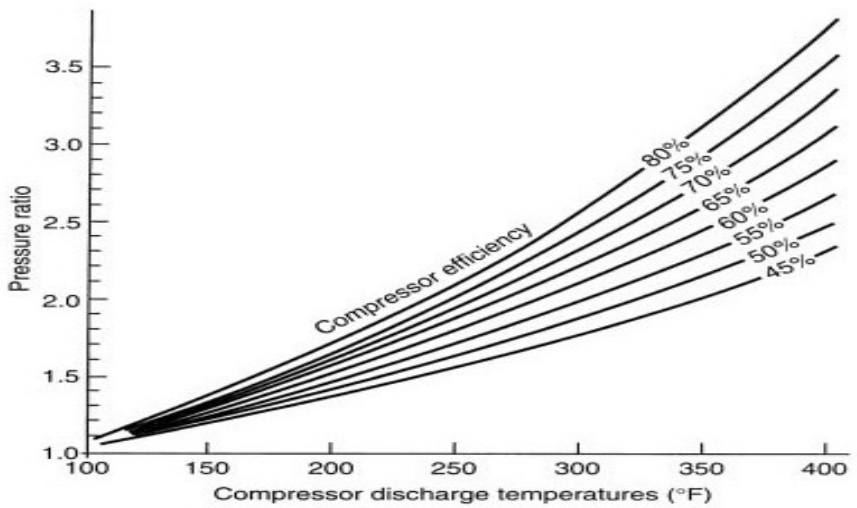

Figure 2

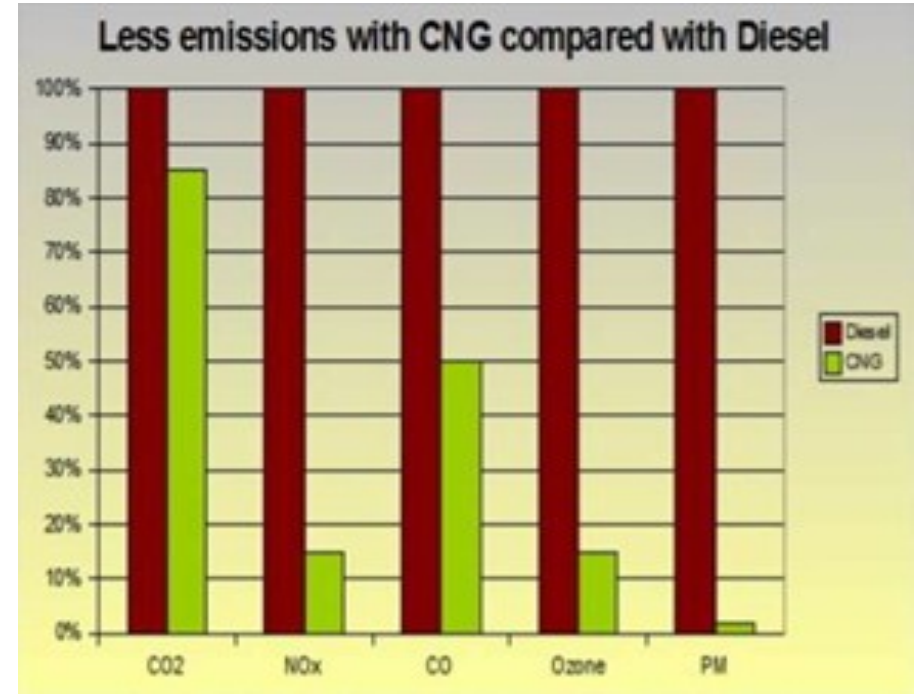

Figure 3

\section{References}

[1]. CNG,"CNG NOW", https:// Cngnow.com

[2]. Liquefied Petroleum Gas, "LPG SPECS”, https://iocl.com/Products/LPGSpecifications.pdf

[3]. Efficiency, “Air Car”,https://auto.howstuffworks.com/fuel-efficiency/vehicles/air-car1.htm

[4]. Compressed Air, "Compressed Air Cars”, https://cleantechnica.com/2013/05/26/compressed-air-cars/ 